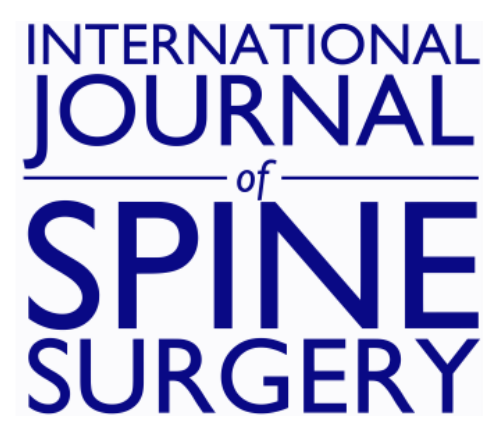

\title{
Trends in the Use of Bone Morphogenetic Protein-2 in Adult Spinal Deformity Surgery: A 10-Year Analysis of 54054 Patients
}

RAFAEL DE LA GARZA RAMOS, JONATHAN NAKHLA, NIKETH BHASHYAM, ADAM E. AMMAR, ALEKA N. SCOCO, MERRIT D. KINON and REZA YASSARI

Int J Spine Surg 2018, 12 (4) 453-459

doi: https://doi.org/10.14444/5054

http://ijssurgery.com/content/12/4/453

This information is current as of April 26, 2023.

Email Alerts Receive free email-alerts when new articles cite this article. Sign up at: http://ijssurgery.com/alerts 


\title{
Trends in the Use of Bone Morphogenetic Protein-2 in Adult Spinal Deformity Surgery: A 10-Year Analysis of 54054 Patients
}

\author{
RAFAEL DE LA GARZA RAMOS, MD, ${ }^{1,2}$ JONATHAN NAKHLA, MD ${ }^{1,2}$ NIKETH BHASHYAM, BS, ${ }^{1,2}$ \\ ADAM E. AMMAR, MD, ${ }^{1,2}$ ALEKA N. SCOCO ${ }^{1,2}$ MERRIT D. KINON, MD ${ }^{1,2}$ REZA YASSARI, MD, MS ${ }^{1,2}$ \\ ${ }^{1}$ Spine Research Group, Montefiore Medical Center/Albert Einstein College of Medicine, Bronx, New York, ${ }^{2}$ Department of Neurological Surgery, Montefiore \\ Medical Center/Albert Einstein College of Medicine, Bronx, New York
}

\begin{abstract}
Background: Bone morphogenetic protein-2 (BMP-2) is an available bone graft option in spinal fusion surgery. The purpose of this study is to investigate the trends of BMP-2 utilization in adult spinal deformity (ASD) surgery.

Methods: The Nationwide Inpatient Sample database from 2002 to 2011 was reviewed. Inclusion criteria were patients over 18 years of age who underwent spinal fusion for ASD. Trends of BMP-2 use were examined over time, as well as stratified based on patient and surgical characteristics. All analyses were done after application of discharge weights to produce national estimates.

Results: There were 54054 patients who met inclusion criteria and were included in this study. The overall rate of BMP-2 use was 39.7\% (95\% confidence interval 35.0\%- 44.3\%). Overall, there was steady increase in its use over time, with the highest peak in 2009 (55.3\% of all cases used BMP-2), and then a decrease up to 37.9\% in $2011(P<.001)$. The rate of BMP-2 use was significantly higher for patients older than 54 years of age (compared to patients $<54, P<.001$ ). It was also higher in females $(P=.009)$, Caucasian patients $(P=.006)$, and Medicare patients $(P=.006)$. Its use was $28.6 \%$ in the Northeast, $38.1 \%$ in the South, $45.2 \%$ in the Midwest, and $48.2 \%$ in the West $(P=.035)$. Circumferential procedures had the highest rate of BMP-2 use $(44.3 \%, P=.045)$. Average total hospital charges were $\$ 152,403 \pm$ 117,454 for patients who did not receive BMP-2 and $\$ 205,426 \pm 137,561$ for patients who did $(P<.001)$.

Conclusion: After analysis of a large nationwide database, it was found that the rate of BMP-2 use in ASD surgery is approximately $40 \%$. There was a significant increase in use from 2002 to 2009, and a decrease thereafter. The highest rates of use were found in older patients, female patients, white patients, Medicare patients, circumferential approaches, and patients undergoing surgery in the Midwest and West regions.
\end{abstract}

Other \& Special Categories

Keywords: adult spinal deformity, bmp-2, trends, Nationwide Inpatient Sample, bone morphogenetic protein

\section{INTRODUCTION}

First discovered in 1965, bone morphogenetic protein-2 (BMP-2) is a protein that functions as a differentiation factor and acts on mesenchymal stem cells to produce bone formation. ${ }^{1}$ Although only approved by the US Food and Drug Administration (FDA) for anterior lumbar interbody fusion with a cage, ${ }^{2}$ the off-label use in spinal fusion surgery has tremendously increased in the past decade. ${ }^{3}$ However, BMP-2 use has been associated, among others, with complications such as seroma, hematoma, and ectopic bone formation, which led the FDA to announce a public health notification in 2008 regarding potential hazards of its use. ${ }^{4}$
Adult spinal deformity is known to affect up to $70 \%$ of the elderly patients, though only a small percentage ultimately require surgical intervention. Long-segment fusions are commonly used for scoliosis correction, but nonunion may affect approximately $17 \%$ of patients. ${ }^{5}$ BMP-2 has been promoted as a potential factor in decreasing the rate of pseudoarthrosis. ${ }^{6}$ Ruofeng et $\mathrm{al}^{2}$ found in a 2015 study that the rate of BMP-2 use in patients over 65 years of age who underwent scoliosis surgery was $35.5 \%$.

The purpose of our study is to analyze the trends in BMP-2 use for scoliosis surgery in patients over 21 years of age over a 10 -year period, using a large nationwide inpatient database. Trends in BMP-2 use based on patient and operative characteristics 
Table 1. Characteristics of patients who underwent adult spinal deformity surgery.

\begin{tabular}{|c|c|}
\hline Characteristic & Value \\
\hline Total cases & 54054 \\
\hline Average age & $59 \pm 15$ \\
\hline \multicolumn{2}{|l|}{ Age group } \\
\hline $21-54$ & $32.5 \%$ \\
\hline $55-64$ & $26.5 \%$ \\
\hline $65-74$ & $27.3 \%$ \\
\hline $75+$ & $13.7 \%$ \\
\hline \multicolumn{2}{|l|}{ Sex } \\
\hline Male & $27.0 \%$ \\
\hline Female & $73.0 \%$ \\
\hline \multicolumn{2}{|l|}{ Insurance } \\
\hline Medicare & $45.1 \%$ \\
\hline Medicaid & $3.8 \%$ \\
\hline Private & $46.9 \%$ \\
\hline Other & $4.2 \%$ \\
\hline \multicolumn{2}{|l|}{ Income quartile } \\
\hline $1 \mathrm{st}$ & $19.5 \%$ \\
\hline 2nd & $25.8 \%$ \\
\hline $3 \mathrm{rd}$ & $27.2 \%$ \\
\hline 4 th & $27.5 \%$ \\
\hline \multicolumn{2}{|l|}{ Hospital region } \\
\hline Northeast & $17.7 \%$ \\
\hline Midwest & $27.6 \%$ \\
\hline South & $41.8 \%$ \\
\hline West & $12.8 \%$ \\
\hline \multicolumn{2}{|c|}{ Hospital teaching status } \\
\hline Nonteaching & $36.9 \%$ \\
\hline Teaching & $63.1 \%$ \\
\hline Revision procedure & $11.6 \%$ \\
\hline Osteotomy & $6.6 \%$ \\
\hline \multicolumn{2}{|l|}{ Approach } \\
\hline Posterior only & $71.2 \%$ \\
\hline Anterior only & $7.8 \%$ \\
\hline Circumferential & $21.0 \%$ \\
\hline \multicolumn{2}{|c|}{ Number of levels fused } \\
\hline$<8$ & $78.3 \%$ \\
\hline $8+$ & $21.7 \%$ \\
\hline
\end{tabular}

are also reported, as well as factors associated with its use.

\section{METHODS}

\section{Study Sample}

The study sample for this investigation derived from the Nationwide Inpatient Sample (NIS) database for the years 2002 to 2011. This database is a government-sponsored inpatient database of all admissions from a $20 \%$ sample of nonfederal hospitals in the country. Given that all admissions from these hospitals are captured, the sample is designed to be nationally representative, and allows for calculation of national estimates using discharge weights (DISCWTs). Over 400 inpatient variables pertaining to demographic data, diagnoses, procedures, hospital charges, and others are captured and allow for analyses of large patient samples. Diagnoses and procedures are encoded in the form of
International Classification of Disease 9th Edition (ICD-9) codes. ${ }^{7}$

For this study, patients with a principal diagnosis of spinal deformity were first identified (ICD-9 codes 737.10, 737.12, 737.19, 737.20, 737.21, 737.20, $737.21,737.22,737.29,737.30,737.32,737.34$, 737.39, 737.40, 737.41, and 737.42). Subsequently, patients who underwent primary or revision fusion procedures were also identified via use of codes 81.00 to 81.09 and 81.31 to 81.39 . Patients younger than 21 years of age and nonelective admissions were excluded. This resulted in 11043 identified cases, which after application of DISCWTs corresponded to 54054 patients.

\section{Collected Data}

Reviewed demographic data included patient age, sex, race, insurance status, estimated median household income, hospital teaching status, and hospital region. Reviewed surgical data included use of BMP-2, revision status (primary versus refusion), use of osteotomy, approach, and number of levels fused. Other reviewed data included total adjusted hospital charges (excluding professional fees) expressed in 2016 US dollars and hospital length of stay.

\section{Statistical Analysis}

All analyses were performed in Stata SE 12 (StataCorp, College Station, Texas) after application of DISCWTs. The survey command in Stata was used for these analyses. Trends over time were analyzed using linear regression. Trends were also analyzed stratified by each of the following: age groups (21-54, 55-64, 65-74, and 75 and older), sex (male versus female), race (white, black, or Hispanic/other), insurance status (Medicare, Medicaid, versus private), hospital region (Northeast, Midwest, South, and West), hospital teaching status (teaching versus nonteaching), type of surgery (primary versus revision), technique (osteotomy versus no osteotomy), and number of levels fused (less than 8 versus 8 or more). Statistical significance was defined as $P<.05$.

\section{RESULTS}

A total of 54054 patients who underwent adult spinal deformity (ASD) surgery between 2002 and 2011 were identified (Table 1). Average age at surgery was $59 \pm 15$ years; $27 \%$ of patients were 


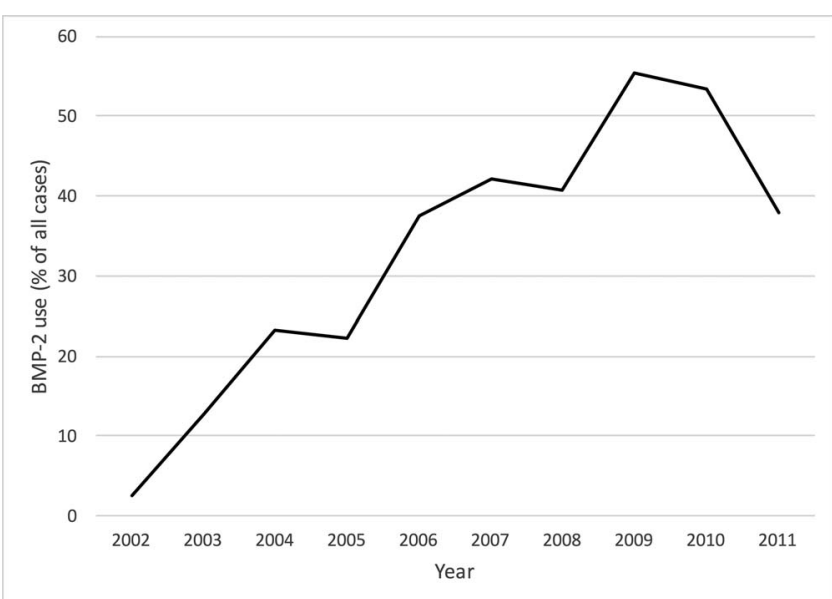

Figure 1. Rate of BMP-2 use over time $(P<.001)$

male and $73 \%$ were female. Almost half of patients had Medicare as insurance $(45.1 \%)$ and the other half had private insurance $(46.9 \%)$. Almost half of patients had surgery in a Southern hospital (41.8\%), followed by the Midwest region (27.6\%). Over twothirds of procedures were performed in teaching hospitals $(63.1 \%), 11.6 \%$ were spinal refusion procedures, osteotomy was performed in $6.6 \%$ of cases, and fusion of 8 or more spinal segments was performed in $21.7 \%$ of all cases.

The overall rate of BMP-2 use was 39.7\% (95\% confidence interval $35.0 \%-44.3 \%$ ). Based on age groups, the overall rate of BMP-2 use was $34.5 \%$ for patients aged 21 to $54,42.6 \%$ for patients aged 55 to $64,42.0 \%$ for patients aged 65 to 74 , and $41.7 \%$ for patients aged 75 or older $(P<.001)$. The rate of BMP-2 use was $40.5 \%$ for females and $37.6 \%$ for males $(P=.009), 41.4 \%$ for white patients, $29.5 \%$ for black patients, and $36.4 \%$ for Hispanic/others $(P=.006)$. When stratified by insurance status, BMP-2 use was $42.7 \%$ for Medicare, $31.8 \%$ for Medicaid, $37.9 \%$ for private insurance, and $34.4 \%$ for others $(P=.006)$; its use was $28.6 \%$ in the Northeast, $45.2 \%$ in the Midwest, $38.1 \%$ in the South, and $48.2 \%$ in the West $(P=.035)$. Teaching hospitals and nonteaching hospitals had similar rates of BMP-2 use (38.1\% versus $42.6 \%, P=.388)$. Its use in primary fusion procedures was $39.3 \%$ versus $42.3 \%$ in revision procedures $(P=.129)$; $39.7 \%$ in nonosteotomy procedures and $38.9 \%$ in osteotomy procedures $(P=.785) ; 39.0 \%$ in posterior-only procedures, $33.6 \%$ in anterior-only procedures, and $44.3 \%$ in circumferential procedures $(P=$ .045 ) and $42.4 \%$ in 1 - to 7 -segment fusions and $47.3 \%$ in $8+$ level fusion procedures $(P=.190)$. Average total hospital charges were $\$ 152,403 \pm$
117,454 for patients who did not receive BMP-2 and $\$ 205,426 \pm 137,561$ for patients who did $(P<.001)$; this corresponded to a $\$ 53,023$ difference.

Overall, there was a significant change in the rate of BMP-2 use over time (Figure 1). Figure 2, A to F, depicts rates of BMP-2 use stratified by age group (A), sex (B), race (C), insurance (D), hospital region (E), and hospital teaching status (F). On the other hand, Figure 3, A to C, depicts rates of BMP-2 use stratified by primary versus revision status (A), use of osteotomy (B), and number of levels fused (C). All changes over time were found to be statistically significant (all $P<.001$ ).

\section{DISCUSSION}

Although initially approved only for anterior lumbar interbody fusion, BMP-2 has been used for posterior lumbar fusion, posterior thoracic fusion, anterior cervical fusion, and posterior cervical fusion; for ASD patients, rates of BMP-2 use are approximately $35.5 \%$ to $61.6 \% .^{2,8}$ In this study, we found a similar rate of $39.7 \%$, with a steady increase in its use up to 2009 and then a decrease thereafter up to 2011.

Ruofeng et $\mathrm{al}^{2}$ reported similar findings in their study of 29787 patients over the age of 65 who underwent posterior long-segment fusion for scoliosis; the rate of BMP-2 use decreased also after 2009. However, Ruofeng et $\mathrm{al}^{2}$ reported an increase after 2010, which is different from our findings. One of the possible explanations for this is that Ruofeng et $\mathrm{al}^{2}$ only looked at posterior instrumentations, whereas our present study also included anterior and circumferential fusions. In fact, the highest rate of BMP-2 use was in patients who underwent anterior-posterior fusion (44.3\%). Similarly, Martin et $\mathrm{al}^{3}$ reported a rapid increase in BMP-2 use for cervical and lumbar fusion operations (degenerative conditions) up to 2008 (involving up to $45.2 \%$ of lumbar and $13.5 \%$ of cervical operations); there was an average annual decrease of $11.7 \%$ thereafter. However, in our current study there was an increase between 2008 and 2009, which likely reflects different practices when using BMP-2 in degenerative conditions (as in the investigation by Martin et $\mathrm{al}^{3}$ ) versus deformity. The decrease in the use of BMP-2 after 2008/2009 is most likely the result of the FDA warning in 2008, which stated that the use of the osteoinductive agent for cervical spine operations was associated with serious and potentially life-threatening complications such as breath- 
A

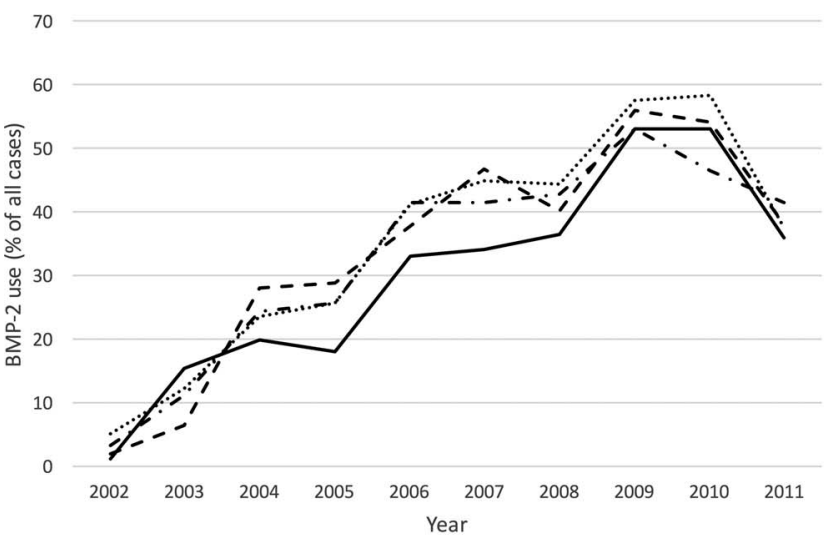

- 21 - 54 years $\cdots \cdots \cdot 55-64$ years $\quad--65-74$ years $\quad-\cdots 75+$ years

C

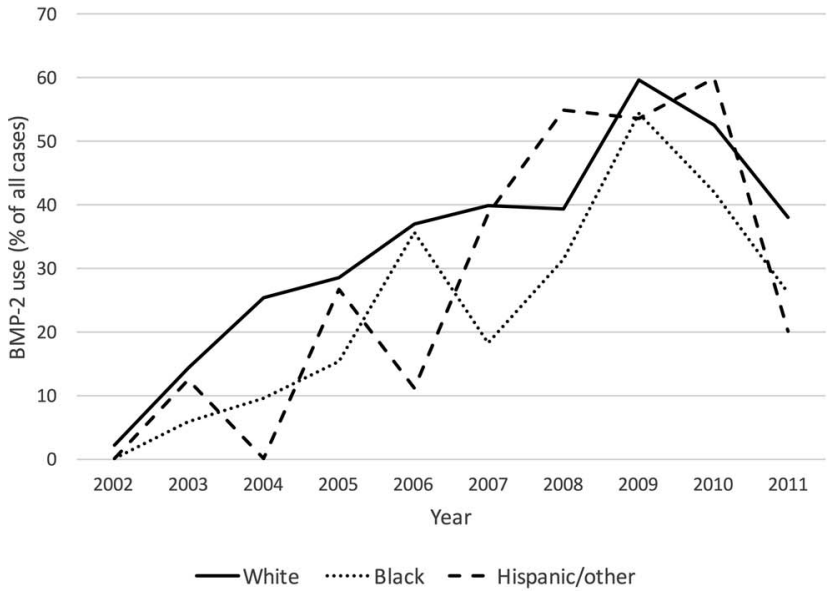

E

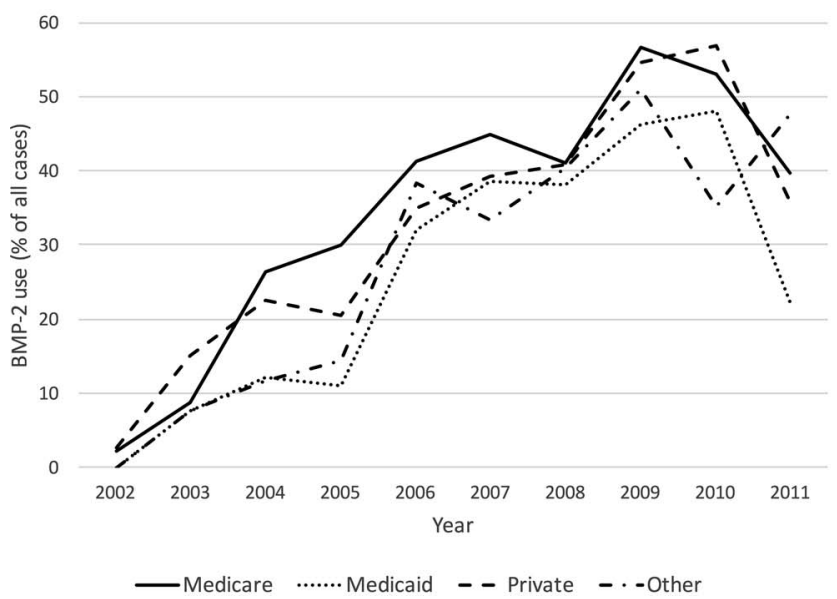

B

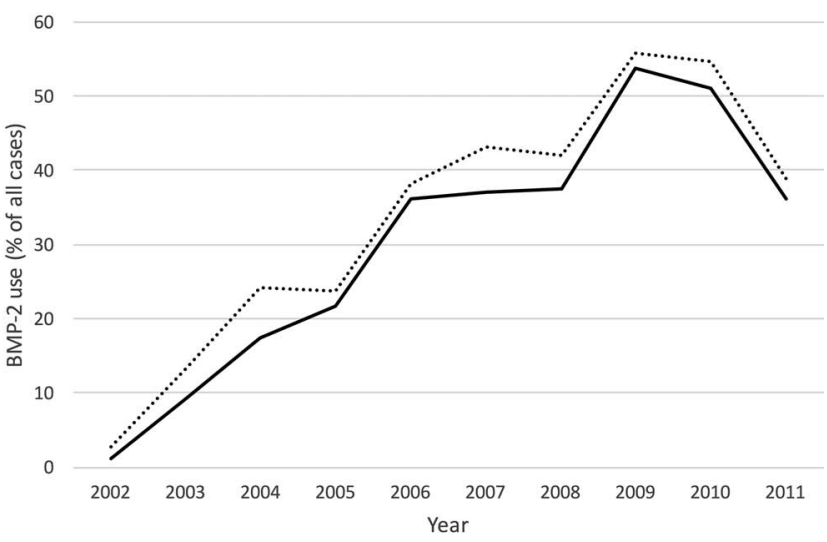

-Male ….... Female

D

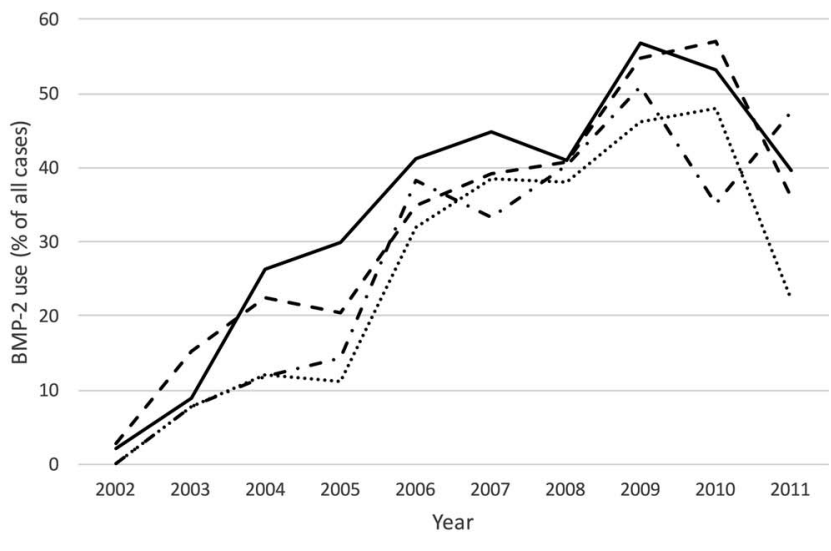

-Medicare …... Medicaid - - Private - - - Other

\section{$\mathrm{F}$}

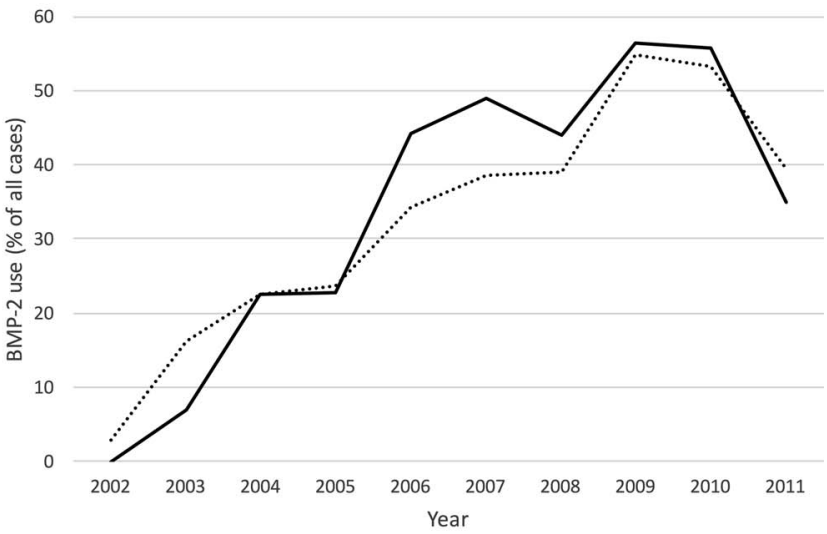

— Non-teaching hospital …... Teaching hospital

Figure 2. Rates of BMP-2 use stratified by (A) age group, (B) sex, (C) race, (D) insurance, (E) hospital region, and (F) hospital teaching status. All changes over time were found to be statistically significant (all $P<.001$ ). 
A

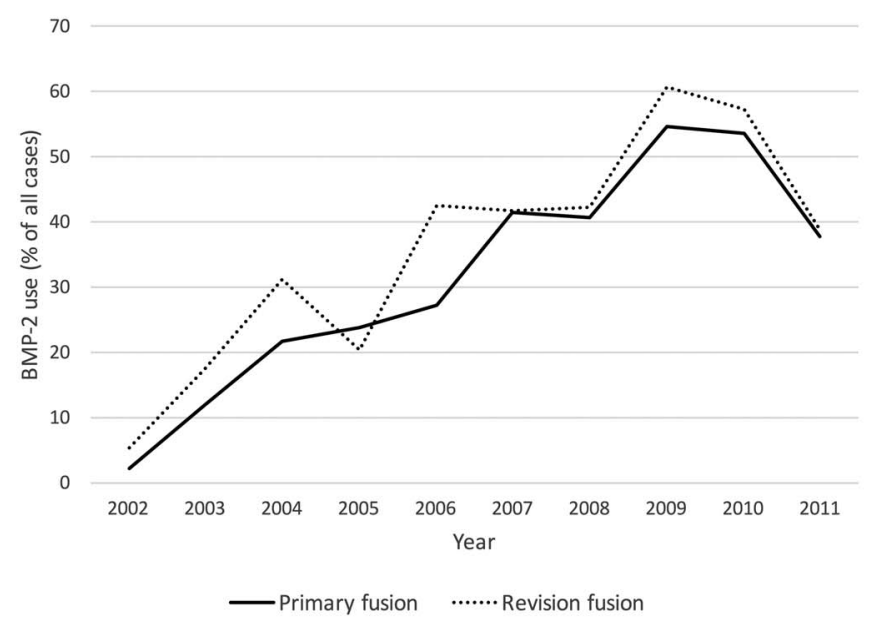

C
B

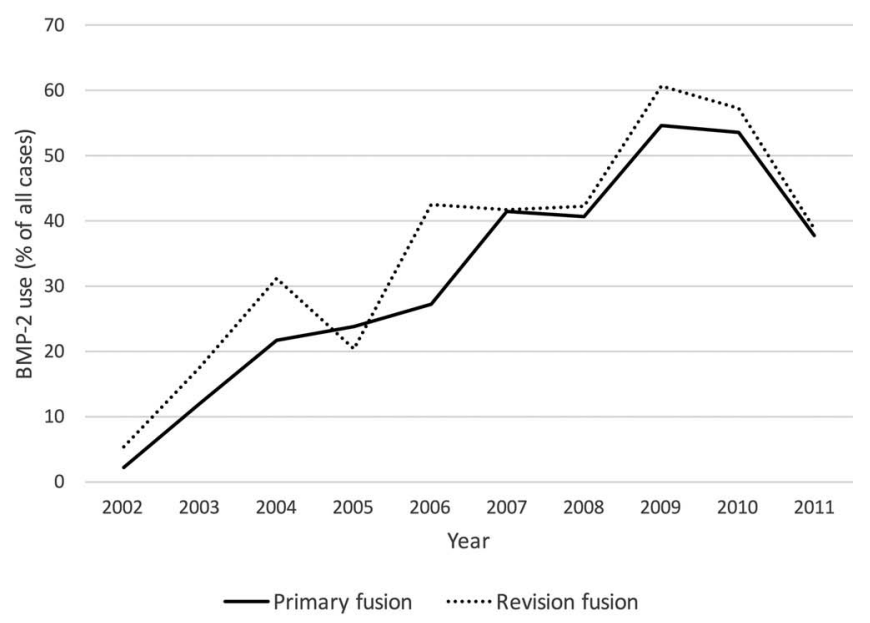

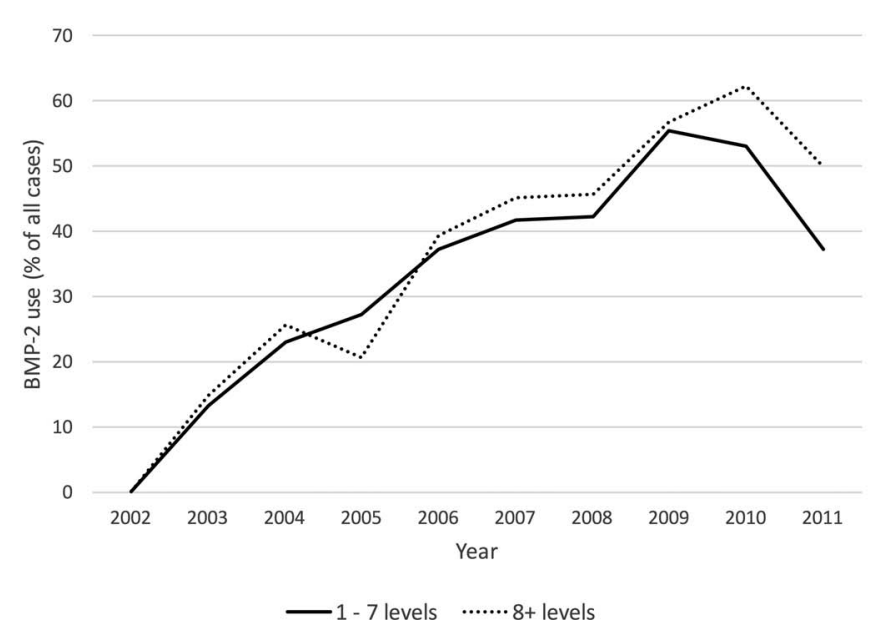

Figure 3. Rates of BMP-2 use stratified by (A) primary versus revision status, (B) use of osteotomy, and (C) number of levels fused. All changes over time were found to be statistically significant (all $P<.001)$.

ing/swallowing difficulty. ${ }^{2}$ Likewise, $\mathrm{McKie}$ et $\mathrm{al}^{9}$ noted a decrease, albeit small, in the use of BMP-2 for anterior cervical fusion after the 2008 warning (5\% decrease compared to the preadvisory era). Although the warning was issued primarily for cervical spine surgery, it is interesting that the use of BMP-2 use also decreased in lumbar degenerative disease and adult deformity surgery.

Nonetheless, the use of BMP-2 in adult scoliosis surgery has not been associated with a significant risk of complications in other investigations. In a report of 279 ASD patients from the International Spine Study Group, authors noted 172 patients $(61.6 \%)$ in whom BMP-2 use was used. ${ }^{8}$ Although patients who received BMP had higher rates of total complications (1.4 versus 0.6 complications per patient) and minor complications (0.9 versus 0.2$)$,
BMP did not increase the risk for acute major, neurological, or wound complications. ${ }^{8}$ Furthermore, the use of BMP-2 has been associated with a significantly decreased risk of reoperation due to pseudoarthrosis after ASD surgery $(5.0 \%$ versus $33.9 \%$ for patients in whom BMP-2 was not used). ${ }^{6}$

When looking at factors associated with BMP-2 use, we found that the use of BMP was higher in patients above 55 years of age, higher in females, white patients, and Medicare patients, and in the Midwest and West regions. Interestingly, the rate of use was not different for primary versus revision procedures, osteotomy versus no osteotomy, or fusion procedures involving less than 8 versus 8 or more segments. These findings suggest that there are certain patient/regional discrepancies in the use of 
BMP, but the exact cause is unknown and warrants further investigation.

Interestingly, the impact of BMP-2 use in hospital charges was significant, increasing the total charges on average by $\$ 53,023$. While it has been shown that its use significantly decreases the need for further revision surgery due to pseudoarthrosis, ${ }^{6}$ a 2007 systematic review on BMP-2 use concluded that there is limited evidence to support greater improvement in clinical outcome for patients who use this agent, and that "the use of BMP for spinal fusion is unlikely to be cost-effective" given the high cost of this product. ${ }^{10}$ Although revision fusion procedures have been found to significantly increase the cost of surgery compared to primary procedures $(\$ 176,809$ versus $\$ 161,791$ in fusion procedures with $4+$ levels), ${ }^{11}$ no formal cost-effectiveness analysis in the ASD population has been performed yet, and this may be the next step in evaluating the long-term efficacy of BMP-2 use in scoliosis surgery. Specifically, it would be interesting to evaluate whether utilizing BMP and potentially preventing need for further revision surgery is more cost effective than not utilizing BMP and potentially increasing the risk for pseudoarthrosis/instrumentation failure.

\section{Limitations}

Although this study provides a large picture of trends of BMP-2 use for ASD surgery over time in the United States, it has several limitations. The use of ICD-9 codes for identification of diagnoses and procedures has risk of miscoding, though the NIS undergoes quality control measures and multiple studies have used this database to examine trends and outcomes in spine surgery. ${ }^{3,9,12-17}$ Another important limitation is that the NIS database is not specific for spine surgery, so variables such as global spinal alignment, radiographic parameters, specifics of implants utilized, and others are unfortunately not available for review.

\section{CONCLUSION}

After analysis of a large nationwide database, it was found that the rate of BMP-2 use in ASD surgery is approximately $40 \%$. There was a significant increase in use from 2002 to 2009, and a decrease thereafter. The highest rates of use were found in older patients, female patients, white patients, Medicare patients, circumferential proce- dures, and patients undergoing surgery in the Midwest and West regions.

\section{REFERENCES}

1. Urist MR. Bone: formation by autoinduction. Science. 1965;150(3698):893-899.

2. Ruofeng Y, Cohen JR, Buser Z, et al. Trends of posterior long segment fusion with and without recombinant human bone morphogenetic protein 2 in patients with scoliosis. Global Spine J. 2016;6(5):422-431.

3. Martin BI, Lurie JD, Tosteson AN, Deyo RA, Farrokhi FR, Mirza SK. Use of bone morphogenetic protein among patients undergoing fusion for degenerative diagnoses in the United States, 2002 to 2012. Spine J. 2015;15(4):692-699.

4. Benglis D, Wang MY, Levi AD. A comprehensive review of the safety profile of bone morphogenetic protein in spine surgery. Neurosurgery. 2008;62(5 Suppl 2):ONS423-431; discussion ONS431.

5. Kim YJ, Bridwell KH, Lenke LG, Cho KJ, Edwards CC II, Rinella AS. Pseudarthrosis in adult spinal deformity following multisegmental instrumentation and arthrodesis. $J$ Bone Joint Surg Am. 2006;88(4):721-728.

6. Paul JC, Lonner BS, Vira S, Kaye ID, Errico TJ. Use of recombinant bone morphogenetic protein is associated with reduced risk of reoperation after spine fusion for adult spinal deformity. Spine (Phila Pa 1976). 2016;41(1):E15-21.

7. Centers for Medicare \& Medicaid Services. ICD-9-CM Diagnosis and Procedure Codes: Abbreviated and Full Code Titles. www.cms.gov/Medicare/Coding/ICD9ProviderDiagnos ticCodes/codes.htm. Accessed February 20, 2017.

8. Bess $\mathrm{S}$, Line $\mathrm{BG}$, Lafage $\mathrm{V}$, et al. Does recombinant human bone morphogenetic protein-2 use in adult spinal deformity increase complications and are complications associated with location of rhBMP-2 use? A prospective, multicenter study of 279 consecutive patients. Spine (Phila Pa 1976). 2014;39(3):233-242.

9. McKie J, Qureshi S, Iatridis J, Egorova N, Cho S, Hecht A. Trends in bone morphogenetic protein usage since the U.S. Food and Drug Administration advisory in 2008: what happens to physician practices when the Food and Drug Administration issues an advisory? Global Spine J. 2014;4(2):7176.

10. Garrison KR, Donell S, Ryder J, et al. Clinical effectiveness and cost-effectiveness of bone morphogenetic proteins in the nonhealing of fractures and spinal fusion: a systematic review. Health Technol Assess. 2007;11(30):1-150, iii-iv.

11. Diebo BG, Passias PG, Marascalchi BJ, et al. Primary versus revision surgery in the setting of adult spinal deformity: a nationwide study on 10,912 patients. Spine (Phila Pa 1976). 2015;40(21):1674-1680.

12. Bernstein DN, Jain A, Brodell D, Li Y, Rubery PT, Mesfin A. Impact of the economic downturn on elective cervical spine surgery in the United States: a national trend analysis, 2003-2013. World Neurosurg. 2016. https://doi.org/10.1016/j. wneu.2016.09.058.

13. Drazin D, Nuno M, Shweikeh F, et al. Outcomes and national trends for the surgical treatment of lumbar spine trauma. Biomed Res Int. 2016;2016:3623875.

14. Thirukumaran CP, Raudenbush B, Li Y, Molinari R, Rubery P, Mesfin A. National trends in the surgical manage- 
ment of adult lumbar isthmic spondylolisthesis: 1998 to 2011. Spine (Phila Pa 1976). 2016;41(6):490-501.

15. De la Garza Ramos R, Goodwin CR, Abu-Bonsrah N, et al. Patient and operative factors associated with complications following adolescent idiopathic scoliosis surgery: an analysis of 36,335 patients from the Nationwide Inpatient Sample. J Neurosurg Pediatr. 2016;25(6):730-736.

16. De la Garza Ramos R, Jain A, Nakhla J, et al. Postoperative morbidity and mortality after elective anterior cervical fusion in patients with chronic and end-stage renal disease. World Neurosurg. 2016;95:480-485.

17. Bydon M, De la Garza-Ramos R, Macki M, Desai A, Gokaslan AK, Bydon A. Incidence of sacral fractures and inhospital postoperative complications in the United States: an analysis of 2002-2011 data. Spine (Phila Pa 1976). 2014;39(18):E11031109.

Disclosures and COI: The manuscript submitted does not contain information about medical device(s)/drug(s). No funds were received in support of this work. The authors have no conflicts of interest.

Corresponding Author: Reza Yassari, MD, MS, Montefiore Medical Center, 3316 Rochambeau Avenue, Bronx, NY 10467. Phone: (718)920-4216; Fax: (718)547-4591; Email: ryassari@montefiore. org.

Published 31 August 2018

This manuscript is generously published free of charge by ISASS, the International Society for the Advancement of Spine Surgery. Copyright (c) 2018 ISASS. To see more or order reprints or permissions, see http://ijssurgery.com. 